\title{
Study on "cold" model of the fluidization process of various types of biomass and its mixture with coal
}

\author{
RAFAIL ISEMIN \\ Tambov State Technical \\ University \\ Sovetskaya st. 106, Tambov, \\ RUSSIA \\ SERGEY KUZMIN \\ Tambov State Technical \\ University \\ Sovetskaya st. 106, Tambov, \\ RUSSIA \\ YURI TEPLITSKII \\ A.V. Luikov Heat and Mass \\ Transfer Institute \\ Brovki st., 15, Minsk \\ BELARUS,
}

\author{
OLEG MILOVANOV \\ Tambov State Technical \\ University \\ Sovetskaya st. 106, Tambov, \\ RUSSIA
}
ALEXANDER MIKHALEV
Tambov State Technical University
Sovetskaya st. 106, Tambov, RUSSIA

\author{
EDUARD BUCHILKO \\ A.V. Luikov Heat and Mass \\ Transfer Institute \\ Brovki st., 15, Minsk \\ BELARUS,
}

\author{
DMITRY KLIMOV \\ Tambov State Technical \\ University \\ Sovetskaya st. 106, Tambov, \\ RUSSIA
}

\author{
ARTEMIY NEBYVAEV \\ Tambov State Technical \\ University \\ Sovetskaya st. 106, Tambov, \\ RUSSIA
}

\author{
ANATOLY GREBENKOV \\ A.V. Luikov Heat and Mass \\ Transfer Institute \\ Brovki st., 15, Minsk \\ BELARUS,
}

\begin{abstract}
The analysis of experimental method for the evaluation of $U_{m f}$ in gas fluidized beds was carried out. It was based on pressure fluctuation measurements in which $U_{m f}$ is determined by the relationship between the standard deviation of pressure measurements and fluid velocity. Unlike previous works, this method was used to determine the minimum fluidization velocity of polydisperse beds of biomass (milled litter), and for beds of mixture of coal ash or sand particles and straw pellets. The experiments were carried out at room temperature in a transparent apparatus with a diameter of $172 \mathrm{~mm}$. It was found that for some mixtures it is impossible to determine $U_{m f}$ from the curve of the pressure drop in the bed on fluid velocity. On the other hand, the method of determining $U_{m f}$ from the relationship between standard deviation of pressure measurements and fluid velocity allows this to be done for all studied beds.
\end{abstract}

Key-Words: - polydisperse bed; minimum fluidization velocity; pressure drop; torrefaction; fluidized bed, biomass and coal mixture.

Received: March 3, 2020. Revised: August 31, 2020. Accepted: September 3, 2020. Published: September 4, 2020.

\section{Introduction}

The concern in use of renewable energy is determined by the problems associated with global warming. Among these sources, the biomass can be considered as a stable source of energy, access to which, unlike, for example, solar energy or wind energy, does not depend on weather conditions, time of day or season. Therefore, the biomass, which includes waste from logging and woodworking, as well as agricultural waste (straw, husks of sunflower, rice, millet and other crops, manure and litter) is increasingly applied in the production of heat and electric energy. It is believed that about 10 $-13 \%$ of the world's thermal and electrical energy is produced using biomass $[1,2,3]$.

A number of thermochemical and biochemical processes is being developed (burning, co-burning with coal, pyrolysis, gasification, torrefaction) using biomass. Some of the processes are carried out in fluidized bed reactors.

Many countries apply coal and biomass co-firing technology in order to reduce greenhouse gas emissions, as well as ash and sulfur oxides [4]. 
Biomass torrefaction is another example of the use of fluidization technology $[5,6,7]$.

Biomass cannot be easily fluidized due to their peculiar shapes, size and densities. For proper fluidization and processing in the reactor, a second solid, usually an inert material (sand, olivine sand, coal ash particles and others) is used to facilitate fluidization of biomass [8]. The fluidization of inert and biomass mixtures is characterized by particles of different shapes, sizes, densities and compositions.

In order to calculate a fluidized bed reactor, it is first necessary to determine the minimum fluidization rate $U_{m f}$, i.e. the gas velocity at which the bed becomes completely fluidized. This velocity is usually determined by the curve of the gas pressure drop in the bed of granular material with increasing or decreasing gas flow through the bed: the gas velocity at which the pressure drop in the bed stops changing is the minimum fluidization rate (Fig.1a). However, in this way $U_{m f}$ can only be determined for monodisperse beds of spherical particles [9].

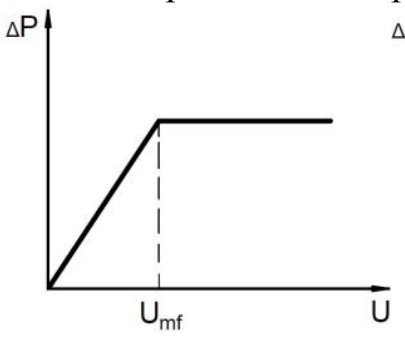

a)

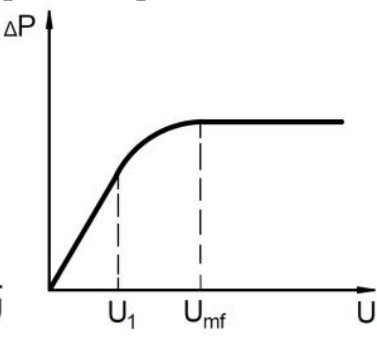

b)
Fig.1. Monodisperse fluidization curves (a) and polydisperse (b) bed.

For binary mixtures of round particles, two velocities are determined in the pressure drop from gas velocity curve: the velocity of start of fluidization of smaller or lighter particles and the velocity of complete fluidization of the binary particle mixture (Fig.1b) [9].

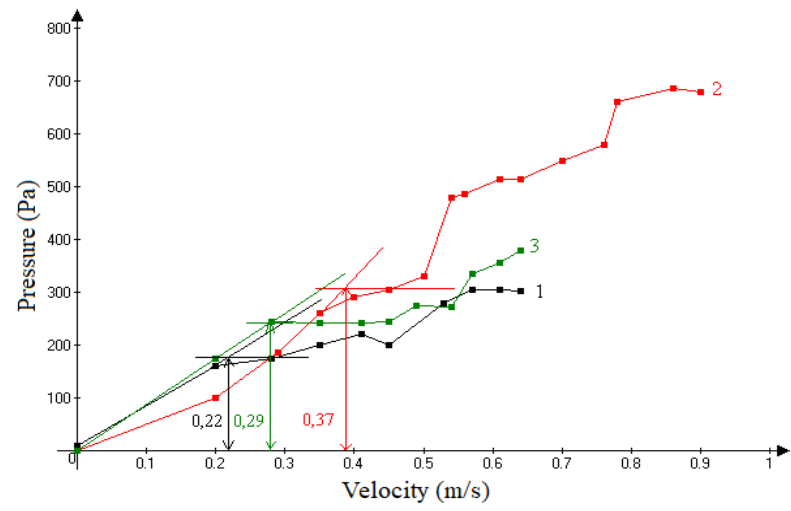

Fig.2 Curves of fluidization process of sawdust (1), rice husk (2) and nuts shell (3).

As can be seen from Fig.2, when fluidizing polydisperse mixtures of irregular shaped biomass particles [10], it is impossible to determine the value of $U_{m f}$ from the curve of pressure drop in the bed from gas velocity.

The so-called Puncochar's method [11-17] is known, which allows determining $U_{m f}$ value according to standard deviation of the pressure drop fluctuations from gas velocity. This is a very simple method for $U_{m f}$ determination. This method can be used not only in laboratory study, but also in industrial fluidized bed reactors.

Unfortunately, Puncochar's method was tested only for beds with a narrow fractional composition [11, $12,14]$ or for a mixture consisting of spherical particles of a narrow fractional composition [13, 17].

In this paper, we wanted to evaluate the possibility of the application of Puncochar's method for determining $U_{m f}$ for polydisperse mixtures of particles of non-spherical shape, which differ acutely in shape, size and weight.

\section{Material and method}

\subsection{Bed material}

Particle beds consisting of the following materials were selected to test Puncochar's method:

1. mixture of particles of coal ash and pellets from straw of winter wheat,

2. polydisperse bed of particles obtained by grinding of bird droppings and straw mixture.

For the study of the fluidization process, we chose a mixture of particles of coal ash and straw pellets because ash can be used as an inert material instead of sand during co-burning of coal and biomass. $62 \%$ of the ash particles had a size of 1.0 to $1.2 \mathrm{~mm}, 21 \%$ of the ash particles were less than $1.0 \mathrm{~mm}, 5.7 \%$ of the ash particles were 1.2 to $1.5 \mathrm{~mm}$ in size and only $11.3 \%$ were more than $1.5 \mathrm{~mm}$. The ash particles had a moisture content of $5.4 \%$ and a density of $1680 \mathrm{~kg} / \mathrm{m}^{3}$.

The ash particles were needle-shaped, and the straw pellets were cylindrical (diameter of $6 \mathrm{~mm}$ and an average length of $12.03 \mathrm{~mm}$ ). The pellet density was 1.4 times lower than the density of ash particles.

The fluidization process of the polydisperse ground particles, representing a mixture of bird droppings and straw, was also studied.

An interest in studying the fluidization process of such particles was caused by the need to develop a technology for disinfecting and processing litter into organic fertilizer or biofuel using the torrefaction method [17].

The particles of litter were close to rounded, and particles of straw were long and thin. Basically, the 
particles of the mixture had a size from 0.3 to 0.6 $\mathrm{mm}(42 \%)$, the proportion of particles larger than $1.25 \mathrm{~mm}$ was $20.3 \%$, the proportion of particles smaller than $0.3 \mathrm{~mm}$ was $37.7 \%$. The bulk density of the mixture of litter with straw comprises 390 $\mathrm{kg} / \mathrm{m}^{3}$. The real particle density of litter with straw implicates $810 \mathrm{~kg} / \mathrm{m}^{3}$.

\subsection{Apparatus}

The experiments were carried out in a round apparatus with a diameter of $300 \mathrm{~mm}$ and a height of $1500 \mathrm{~mm}$. The apparatus is constructed in the form of a column of acrylic glass, which allows visual observations. The column rested on an air distribution grid, which represented a bed of $60 \mathrm{~mm}$ high from $5.0 \mathrm{~mm}$ diameter silica gel particles clutched between two metal grids. The apparatus with an air distribution grid rested on an air intake chamber filled with Raschig rings to even the air flow.

Air was pumped into the apparatus by HRD - 60/4 fan with a pressure of $8000 \mathrm{~Pa}$. The air flow was regulated by means of a valve installed on the bypass pipe, directing the air flow bypassing the installation. The air temperature was $20-24^{\circ} \mathrm{C}$.

The air velocity was measured at the outlet of the apparatus with Delta-OHM HD 2103-1 hot-wire anemometer. In each experiment, at least fifty measurements of air velocity were carried out.

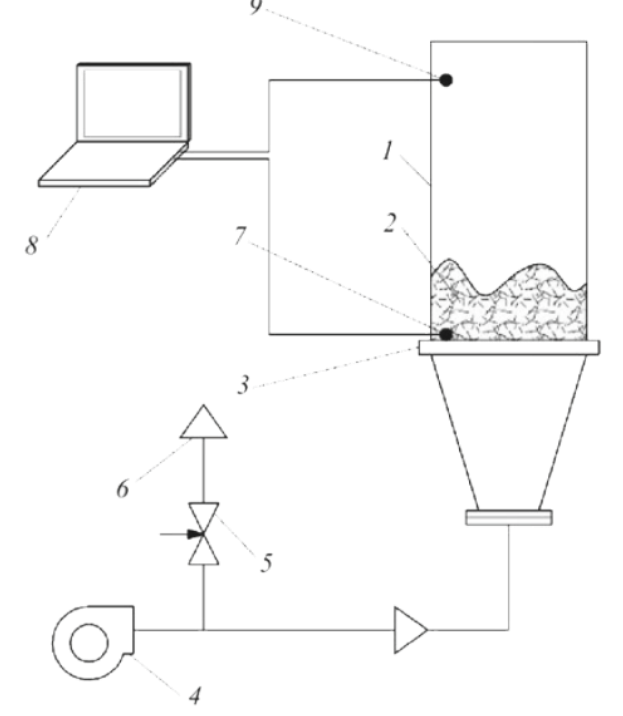

Fig.3 Experimental setup scheme.

1) Apparatus with a fluidized bed; 2) fluidized bed of biomass and coal ash particles; 3 ) airdistribution grid; 4) blower; 5) control valve installed on the bypass pipe, 6) air release to the atmosphere to control the rate of flow of the air for fluidization; 7) differential-micromanometer
Testo-521; 8) personal computer; 9) hot-wireanemometer sensor of Delta-OHM HD 2103-1.

The pressure drop in the bed was measured using Testo-521 differential micromanometer. The primary sensor, made in the form of a needle with an inner diameter of $0.5 \mathrm{~mm}$ and a length of $60 \mathrm{~mm}$, was placed $5 \mathrm{~mm}$ above the air distribution grid in the center of the apparatus. The micromanometer Testo-521 was connected to the primary sensor with a plastic tube with an inner diameter of $4 \mathrm{~mm}$ and a length of $300 \mathrm{~mm}$. The experimental setup is shown in Fig.3.

It was shown in $[18,19]$ that for beds of large particles the location of the sensor practically does not affect the value of the standard deviation of the pulsation of the pressure drop and the carrier frequency in the pulsations of the pressure drop.

It was shown in work [20] that the location of the sensor does not significantly affect the amplitude of the pressure drop pulsation for beds of small particles of Geldart A and B groups. Since our study considers the behavior of very large particles (Geldart D group) at room temperature, we can limit ourselves to the location of only one sensor in the bed in the immediate closeness of the air distribution grid.

\subsection{Experimental Procedure}

The experiments were carried out at room temperature.

In the study of the process of joint fluidization of coal ash particles and straw pellets, the height of the fixed bed was constant and amounted to $175 \mathrm{~mm}$.

When studying the fluidization process of a polydisperse bed consisting of crushed particles of litter and straw, and a mixture of particles of quartz and olivine sand, the initial bed height was $90 \mathrm{~mm}$, $150 \mathrm{~mm}$, and $175 \mathrm{~mm}$.

Conducting experiments with all beds of particles, the bed was transferred to the active fluidized state, which was recorded by visual observation through the transparent wall of the apparatus. Then, the flow rate of air blown through the bed was started to decrease, and the pulsations of the pressure drop across the bed were measured at various air flow rates.

The pressure drop in the bed was also measured and the curves of the pressure drop in the bed from air velocity were constructed.

The analysis of the literature data shows that various researchers do not have a unified approach to choosing the duration of the interval for measuring fluctuations in the pressure drop in the bed and the 
pause between measurements. So, in work [21], the pressure drop in a bed of small particles is measured within 128 seconds. Herewith, the authors received 1024 values from each sensor (measurements were taken after 0.125 seconds). In work [22], in a bed with a mixture of small and nanoparticles, pressure drop pulsations were measured for 25 seconds every 0.005 seconds. When working with mixtures of large, small, and very small particles [3], the pressure measurements were taken after 0.005 seconds, but only 5.12 seconds. In [6], in a bed of very large particles, pressure drops were measured every 0.01 seconds for 100 seconds.

In determining the necessary duration and frequency of measuring the pressure drop in the bed, we proceeded from the fact that a decrease in the frequency of measurement and the duration of each experiment should not lead to a significant (more than $10 \%$ ) change in the value of the mathematical expectation of the random process of the pressure drop change in the bed and the value standard deviation from this mathematical expectation. It was found that without reducing the measurement accuracy by more than $10 \%$, the measurement of the pressure drop pulsation should be made every 0.04 seconds for 60 seconds. The actual time of measurement of pressure fluctuation pulsations was 180 seconds, which made it possible to obtain reliable experimental data.

The resulted set of random values of the pressure
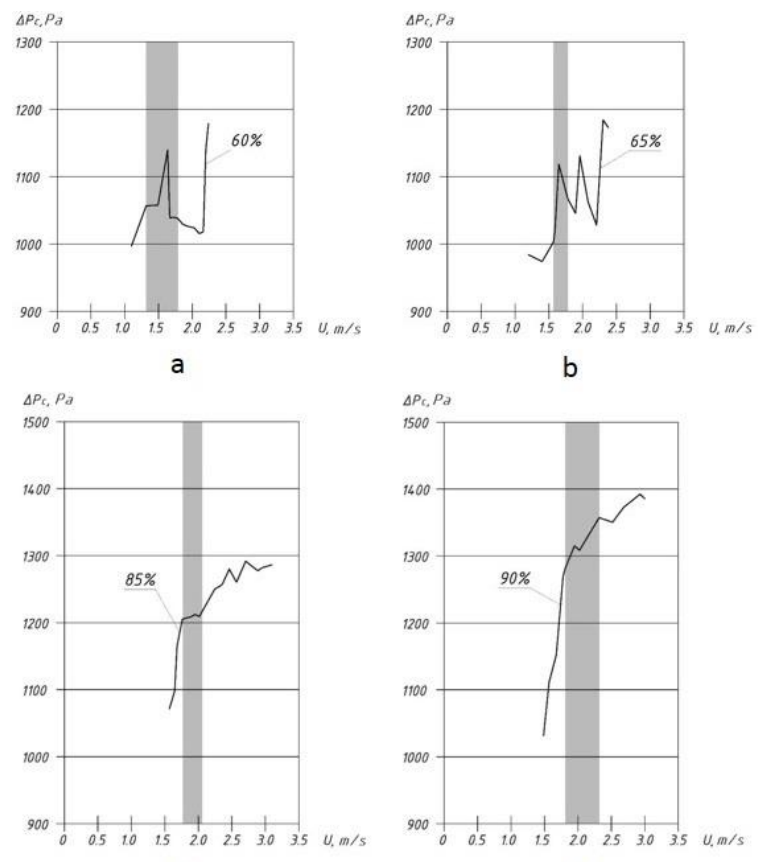

e b

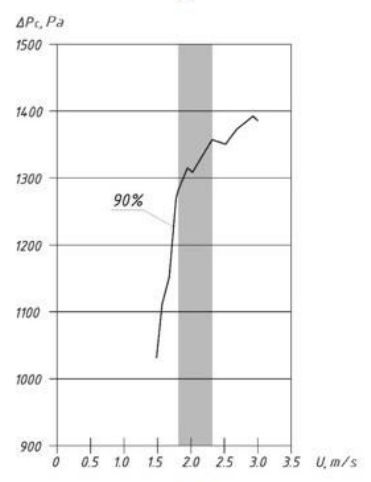

$\mathrm{f}$

drop in the bed was exposed to mathematical processing. The average value of the pressure drop in the bed during the observation time was determined by equation (1):

$$
\Delta P_{c}=\sum \Delta P_{j} / N
$$

where: $\Delta P_{j}$ - value of $j$ measurement of pressure drop; $N$ - number of measurements.

The standard deviation of the $\Delta P_{c}$ was calculated by equation (2):

$$
\sigma=\left[\sum\left(\Delta \mathrm{P}_{j}-\Delta \mathrm{P}_{c}\right)^{2} / \mathrm{N}\right]^{1 / 2}
$$

\section{Results and discussion}

The study of the process of joint fluidization of coal ash particles and straw pellets.

Preliminary experiments showed that with a content of more than $40 \%$ (by weight) of ash particles in the mixture, no joint fluidization of ash particles and straw pellets was observed. Therefore, in the future, we analyzed only the data obtained for mixtures containing more than $60 \%$ straw pellets and the corresponding amount of ash particles.

Fig.4 shows the dependence of the $\Delta P$ vs $U$ for different content of mixtures of ash particles and pellets.

A dark bar in the graphs indicates the range between the velocity of the beginning of fluidization and the minimum velocity of fluidization. This velocity range was determined using visual observations of
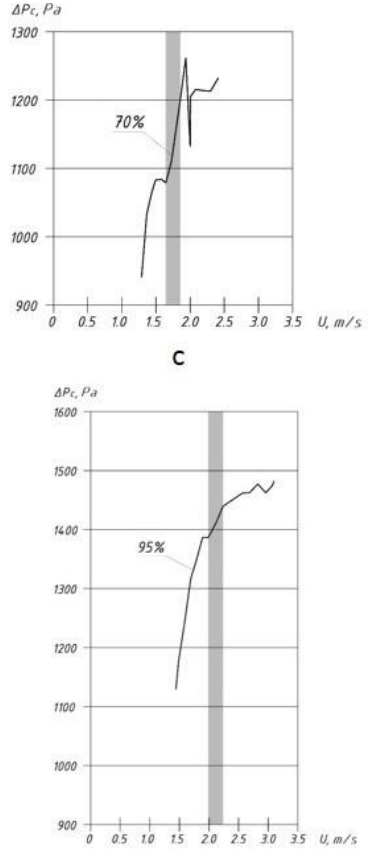

$\mathrm{g}$
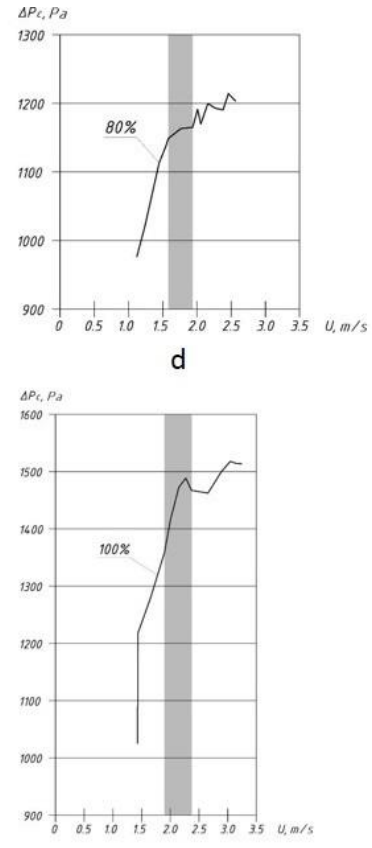

$\mathrm{h}$

Fig.4. Dependence of pressure drop in the bed on the air velocity for the mixture consisting of: a) 60 and $40 \%$, b) 65 and $35 \%$, c) 70 and $30 \%$, d) 80 and $20 \%$, e) 85 and $15 \%$, f) 90 and $10 \%$, g) 95 and 5\%, h) $100 \%$ and $0 \%$, respectively, pellets and coal ash particles. 
the state of the bed.

The $U_{m f}$ onset decreases with an increase in the fraction of coal ash particles: for a bed of pellets $(100 \%)$ the $U_{m f}$ is $2.4 \mathrm{~m} / \mathrm{s}$, for a bed containing $15 \%$ coal ash $U_{m f}-2.1 \mathrm{~m} / \mathrm{s}$, for a bed containing $35 \% U_{m f}$ $1.75 \mathrm{~m} / \mathrm{s}$.

The comparison of the results of visual observations and the graph of the dependence of the $\Delta P$ vs $U$ (such graph is usually applied to experimentally estimate the value of the minimum fluidization velocity) shows that it is extremely difficult to use the graph of the dependence $\Delta P_{c}=f(U)$ for determining the Umf of a mixture of coal particles and straw pellets. Moreover, the larger the proportion of ash particles in the mixture, the more difficult it is to accomplish it.

The section of the curve $\Delta P_{c}=f(U)$, parallel to the abscissa axis and corresponding to the state of fluidization of the bed, is not observed. Moreover, in some cases, several peaks are noted on $\Delta P_{c}=\mathrm{f}(U)$ dependence curve, which obviously correspond to the transition to the fluidized state of individual fractions. It is impossible to determine the value of the air velocity from these curves, which would correspond to the complete fluidization of the bed.

So the use of a well-known and widely used method for determining the minimum fluidization rate is not possible in the case of joint fluidization of pellets from straw and coal ash particles at a high concentration of these ash particles in the mixture.

Fig. 5 shows the dependences of the $\sigma$ vs $U$ for different content of ash and pellet mixtures. The values of standard deviation lie in the range of 0 $25 \mathrm{~Pa}$.

As follows from the consideration of these figures, for mixtures containing from 70 to $100 \%$ pellets, the dependence $\sigma=f(U)$ can be divided into three sections: the section, which corresponds to a fixed bed $(\sigma=0)$, the section, which corresponds to the beginning of the transition of the bed to the fluidized state and the section where the rapid growth of $\sigma$ with increasing $U$ is observed (completely fluidization). For mixtures containing less than $70 \%$ of the granules, the first section is practically absent, but the second and third sections are clearly distinguished. The air velocity corresponding to the transition of the dependence $\sigma=f(U)$ from the first to the second section is the velocity at which fluidization just begins. The air velocity corresponding to the transition of the dependence $\sigma=f(U)$ from the second to the third section, as can be seen from the graphs, is the velocity where the bed becomes completely fluidized. As follows from Figure 5, at the full fluidization of the bed the curve of $\sigma$ vs. $f(U)$ relation can be approximated by a straight line, i.e. $(\mathrm{d} \sigma / \mathrm{d} U)=$ const.

Therefore, the curve of $\sigma$ vs. $f(U)$ relation, at least for straw pellets and ash particles can be used for experimental estimation of $U_{m f}$.

The study of the process of joint fluidization of crushed particles of poultry litter and straw.

Fig. 6 shows the curves of the pressure drop in the bed of particles of crushed litter and straw from the

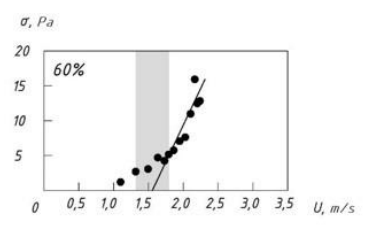

a

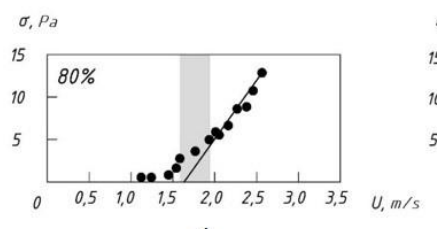

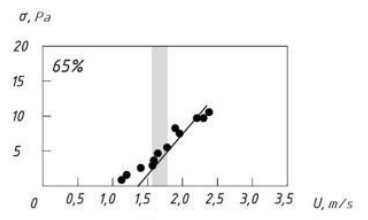

b

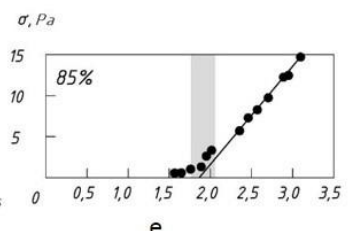

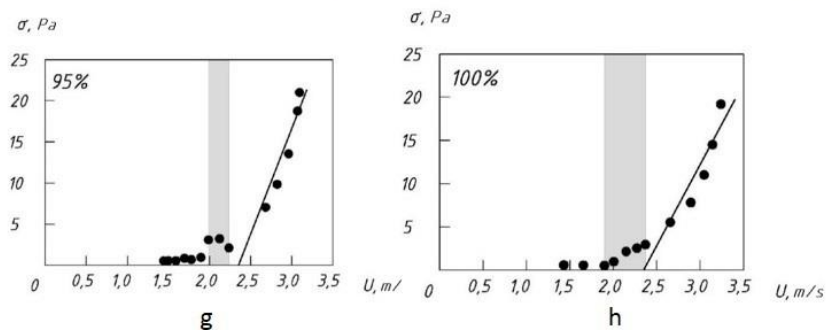

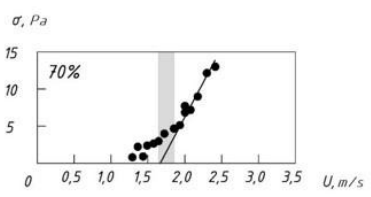

c

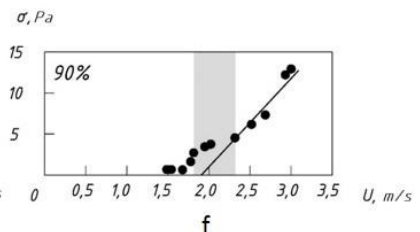

Fig.5 Dependence of the standard deviation of fluctuations in pressure drop on air velocity for a mixture of straw pellets and ash particles consisting of: a) 60 and 40\%, b) 65 and 35\%, c) 70 and 30\%,d) 80 and 20\%, e) 85 and $15 \%$, f) 90 and $10 \%$, g) 95 and 5\%,h) $100 \%$ and $0 \%$, respectively, pellets and particles of coal ash. 
velocity of air blown through the bed.

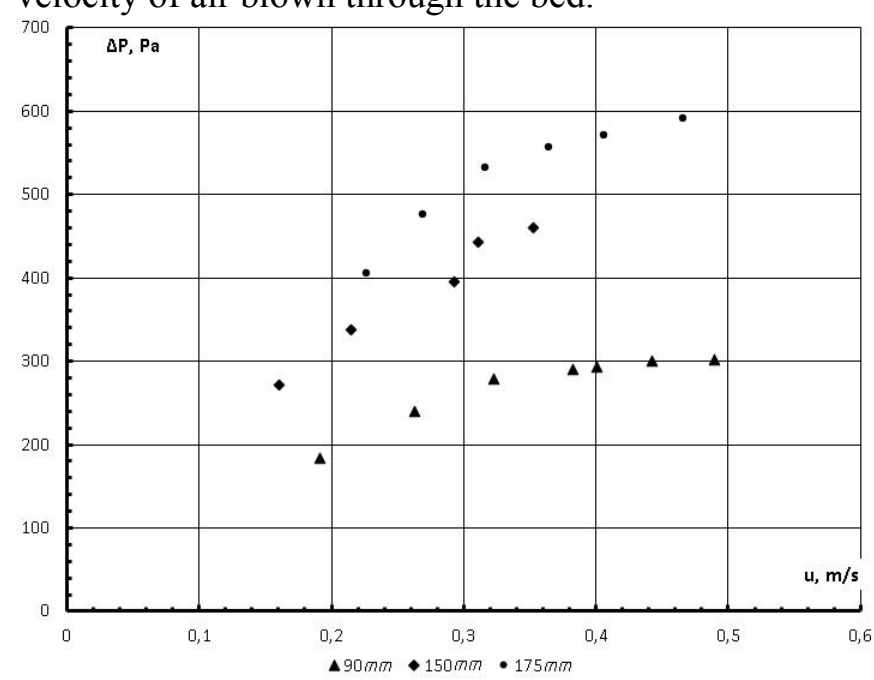

Fig.6 Dependence of pressure drop in bed of crushed poultry litter particles and straw on velocity of air blown through the bed

As can be seen from Fig.6, it is possible only with a small height of the bed $(90 \mathrm{~mm})$ to determine the value of the minimum fluidization rate for the studied particles.

At an initial bed height of more than $90 \mathrm{~mm}$, a monotonic increase in the pressure drop in the bed is observed with an increase in the speed of air blown through the bed. This makes it impossible to determine the value of the air velocity at which the bed passes into a fluidized state, from the dependence of the pressure drop in the bed on the speed of the air blown through the bed.

Fig. 7 shows the curves of variation of the $\sigma$ from the velocity of air $U$.

The values of the $\sigma$ vary in the range of $0-10 \mathrm{~Pa}$, i.e. the pulsations of the $\Delta P$ in the bed consisting of a mixture of particles of crushed litter and straw are approximately two times less intense than in the bed of particles of coal ash and straw pellets.

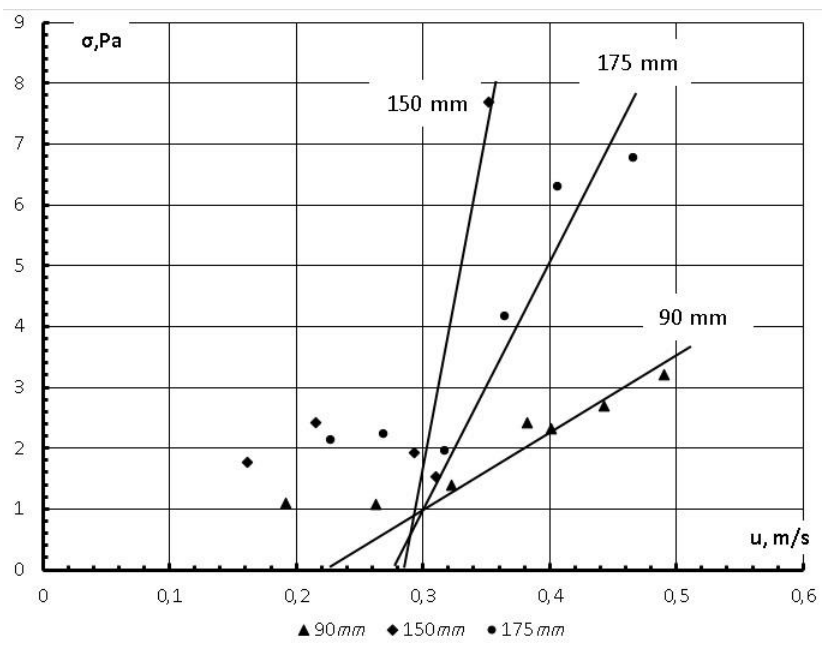

Fig.7 Curves of changes in standard deviation of fluctuations of pressure drop in bed on velocity of air blown through bed.

Fig.7 shows that, in the same way as the bed consisting of coal ash particles and straw pellets, when the bed of particles of crushed litter and straw goes into a fluidized state, a sharp increase of the $\sigma$ of the $\Delta P$ pulsation and Puncochar's method can be applied to determine the $U_{m f}$.

Moreover, Puncochar's method makes it easier and more accurate to determine the value of the $U_{m f}$ rate than determining the $U_{m f}$ by the dependence of the $\Delta P$ from the $U$.

As can be seen from Fig.5 and Fig.7, in the fluidization of beds of polydisperse particles, which differ sharply from each other in shape, size, density, and at air velocities less than $U_{m f}$, the values of $\sigma$ are not equal to zero, as in the case of fluidization of particles of a spherical shape and a narrow fractional content as it was in work [11].

Therefore, Puncochar's method for the determination of the $U_{m f}$ must be clarified in relation to polydisperse beds.

The following algorithm for $U_{m f}$ determination is proposed:

(1) pulsations of the $\Delta P$ are measured at several values of the gas velocity;

(2) the values of the $\sigma$ of the $\Delta P$ pulsation are determined for two values of the gas velocity $U$;

(3) the method of numerical differentiation determines the values of the derivative $\left[\Delta\left(\sigma_{\mathrm{i}}-\sigma_{\mathrm{i}-1}\right) /\left(U_{\mathrm{i}}-U_{\mathrm{i}-1}\right)\right]$

(4) two gas velocity values are selected for which $(\mathrm{d} \sigma / \mathrm{d} U)=$ const is true;

(5) the values of $\sigma$ corresponding to the gas velocities mentioned in (4) are applied on the dependence $\sigma=f(U)$. A straight line is drawn through these two points until it intersects with the abscissa axis;

(6) the $U$, which corresponding to this intersection is the velocity of complete fluidization of the multicomponent bed at room temperature.

\section{Conclusion}

The paper investigates the process of transition to a fluidized state of polydisperse beds consisting of particles that differ sharply from each other in shape and size: mixture of particles of coal ash and pellets from straw of winter wheat and polydisperse bed of particles obtained by grinding of bird droppings and straw mixture.

An attempt to determine the value of the minimum fluidization rate from the curve of the dependence of 
the change in the pressure drop in the bed on the velocity of the gas blown through the bed in some cases did not lead to success (with a large fraction of coal ash particles or with a large initial bed height of particles obtained by grinding of bird droppings and straw mixture).

On the curve of the dependence of the pressure drop in the bed on the velocity of the gas blown through the bed, there was no horizontal section that would correspond to the transition of the bed to the fluidized state, while the transition of the bed to the fluidized state was confirmed by visual observations.

On the other hand, the use of the Puncochar's method made it easy to determine the value of the minimum fluidization rate for any fractional composition of the studied mixtures of particles.

At the same time, it was found that for some particle mixtures it is impossible to determine the value of the minimum fluidization rate from the curve of the pressure drop from the velocity of air blown through the bed. Then, as Puncochar's method makes it easy to do for all researched mixtures of particles.

The transition to a fluidized state of polydisperse particles, which differ sharply in shape, size and density, is accompanied by fluidization of individual fractions of particles. Therefore, the values of $\sigma$ at air velocities less than $U_{m f}$ are not equal to zero. This required the development of a new $U_{m f}$ detection algorithm applying Puncochar's method. A new algorithm for using the Puncochar's method to determine the minimum fluidization rate of polydisperse mixtures of particles that differ sharply from each other in shape and size was developed and tested by us experimentally in relation to the studied mixtures of particles.

In our opinion, Puncochar's method can be used not only in experimental but also in industrial installations. Very often, the fractional composition of the bed changes during the thermal treatment of fuel in a fluidized bed (combustion, gasification, pyrolysis), including due to ash melting and agglomeration of ash particles and fuel. This leads to the fact that the minimum fluidization rate for the mixture of particles that currently exists in the fluidized bed is higher than the calculated one. This, under certain conditions, can lead to the bed defluidization.

Puncochar's method, in our opinion, allows to estimate the actual value of the minimum fluidization rate for the fractional composition of particles that exists in the bed at a given moment of time.

For this, it is necessary to use our proposed algorithm for determining the minimum fluidization rate and determine the values of $\sigma$ for two velocities of the gas blown through the bed. In this case, the deposition of the bed, i.e. the transfer of the particle bed to a stationary state, and shutdown of the fluidized bed reactor is not required.

Acknowledgements. The reported study was funded by RFBR and Tambov region according to the research project № 19-48-680006.

\section{References:}

[1] Cui H., Grace J.R., Fluidization of biomass particles: A review of experimental multiphase flow aspects, Chemical Engineering Science, 62, 2007, p. 45-55.

[2] Heidenreich S., Foscolo P.U., New concepts in biomass gasification, Progress in Energy and Combustion Science, 46, 2015, pp.72-95.

[3] Saidur R., Abdelaziz E.A., Demirbas A., Hossain M.S., Mekhilef S., A review on biomass as a fuel for boilers, Renewable and Sustainable Energy Reviews, 15, 2011, pp. 2262-2289.

[4] Werther J., Potential of biomass co-combustion in coal-fired boilers, Proceeding of the 20th International Conference on Fluidized Bed Combustion, 2009, pp. 27-42.

[5] Wang Z., Jim Lim C., Grace J.R., Biomass torrefaction in a slot-rectangular spouted bed reactor, Particuology, 42, 2019, pp. 154-162.

[6] Li H., Liu X., Legros R., Bi X.T., Lim C.J., Sokhansanj S., Torrefaction of sawdust in a fluidized bed reactor, Bioresource Technology, 103, 2012, pp. 453-458.

[7] Atienza-Martínez M., Fonts I., Ábrego J., Ceamanos J., Gea G., Sewage sludge torrefaction in a fluidized bed reactor, Chemical Engineering Journal, 222, 2013, pp. 534-545.

[8] Rao T.R., Bheemarasetti Ram J.V., Minimum fluidization velocities of mixture of biomass and sands, Energy, 26, 2001, pp. 677-644.

[9] Aerov M.E., Todes O.M., Hydraulic and thermal fundamentals of operation of devices with a stationary and fluidized granular bed, Chemistry, 1968.

[10] Abdullah M.Z, Husain Z., Yin Pong S.L., Analysis of cold flow fluidization test results for various biomass fuels, Biomass and Bioenergy, 24, 2003, pp. 487-494.

[11] Puncochar M., Drahos J., Cermak J., Selucky K., Evalution of minimum fluidizing velocity in gas fluidized bed from pressure fluctuations, Chemical Engineering Communications, 35(16), 1985, pp. 81-87. 
[12] Leu L.P., Lan Ch.-W., Measurement of pressure fluctuations in two - dimensional gas - solid fluidized beds at elevated temperatures, Journal of Chemical Engineering of Japan, 23(5), 1990, pp. 555-562.

[13] Li Z., Kobayashi N., Nishimura A., Hasatani M., Sorption drying of soybean seeds with silica gel. I. Hydrodynamics of fluidized bed dryer, Drying technology, 20(6), 2002, pp. 1193-1213.

[14] Felipe C.A.S., Rocha S.C.S., Prediction of minimum fluidization velocity of gas-solid fluidized beds by pressure fluctuation measurements - Analysis of the standard deviation methodology, Powder Technology, 174, 2007, pp. 104-113.

[15] Hong S.C, Jo B.R., Doh D.S., Choi C.S., Determination of minimum fluidization velocity by the statistical analysis of pressure fluctuations in a gas-solid fluidized bed, Powder Technology, 60, 1990, pp. 215-221.

[16] Leu Lii-P., Wu Chih-N., Prediction of pressure fluctuations and minimum fluidization velocity of binary mixtures of Geldart group B particles in bubbling fluidized beds, Can. J. Chem. Eng., 78, 2000, pp. 578-584.

[17] Isemin R., Mikhalev A., Milovanov O., Stepantsova L., Solopov V., Development of the Technology of Poultry Litter Treatment into Organics Fertilizer through its
Decontamination by the Low - Temperature Pyrolysis Method, International Journal of Chemical Engineering and Application, 8(3), 2017, pp. 144-188.

[18] Scala F., Chirone R., Characterization and Early detection of Bed Agglomeration during the Fluidized Bed Combustion of Olive Husk, Energy \& Fuel, 20, 2006, pp. 120-132.

[19] Zhang J., Lü J., Wang X., Zhang H., Yue G., Suda T., Sato J., Characterization of Pressure Signals in Fluidized Beds Loaded with Large Particles Using Wigner Distribution Analysis: Feasibility of Diagnosis of Agglomeration, Chin. J. Chem. Eng., 15(1), 2007, pp. 24 -29.

[20] Parise M.R, Kurka P.R.G., Taranto O.P., Identification of Defluidization Region in a Gas-Solid Fluidized Bed Using Method on Pressure Fluctuation, Brazilian Journal of Chemical Engineering, 20(3), 2009, pp. 537543.

[21] Jang H.T, Kim S.B, Cha W.S., Prediction of take-over velocity of a binary density system using pressure fluctuations in a fluidized bed, Journal of Chemical Engineering of Japan, 39(9), 2006, pp. 924-931.

[22] Kim J.-S, Tsutsumi A, Kang Y., Influences of nano particle addition on hydrodynamics and heat transfer in gas-solids fluidized beds, Journal of Chemical Engineering of Japan, 41(7), 2008, pp. 670-677.

\section{Creative Commons Attribution License 4.0 (Attribution 4.0 International, CC BY 4.0)}

This article is published under the terms of the Creative Commons Attribution License 4.0

https://creativecommons.org/licenses/by/4.0/deed.en_US 